\title{
The role of stereotactic radiosurgery in the management of secondary pontine tumors
}

\author{
loannis N. Mavridis* \\ Department of Neurosurgery, "K.A.T.-N.R.C." General Hospital of Attica, Athens, Greece
}

Received: June 9, 2015

Accepted: July 13, 2015

Online Published: August 8, 2015

DOI: $10.5430 /$ css.v1n1p15

URL: http://dx.doi.org/10.5430/css.v1n1p15

\begin{abstract}
Brainstem metastasis is an uncommon complication of systemic cancer and is generally considered to have a highly unfavorable prognosis. Regarding its management, stereotactic radiosurgery (SRS) is nowadays used as a feasible treatment option and is expected to achieve a radical cure. The pons is the commonest location of brainstem metastases (primarily from lung cancer), with a frequency ranging from $51.9 \%$ to $79.3 \%$. The purpose of this review is to explore the role of radiosurgery in the management of pontine metastases. Methodologically, a combined PubMed search was mainly applied for the terms "radiosurgery" and "pontine metastases". Beside other treatment efforts, SRS has a major role in the management of patients with secondary pontine tumors, as a safe and effective treatment option that prolongs survival with low complications rate. The mean dose used for this purpose is approximately $17 \mathrm{~Gy}$ and the achieved median survival of the treated patients is nearly 9 months. Although larger lesions as well as melanoma and renal cancer usually have a worse prognosis, the patient's clinical status seems to be more important in determining survival. SRS is currently a principal treatment option for patients suffering from pontine metastases.
\end{abstract}

Key Words: Brainstem, Cerebral metastases, Gamma Knife, Pons, Stereotactic radiosurgery, Survival

\section{INTRODUCTION}

The most frequent origins of cerebral metastases include lung cancer, breast cancer, renal cancer, gastrointestinal cancer and melanoma. Considering their treatment, surgery, radiotherapy and occasionally chemotherapy are traditionally applied. ${ }^{[1]}$ Focusing on the use of radiotherapy, longterm survivors with brain metastases are at risk for neurologic morbidity after whole-brain radiotherapy (WBRT). ${ }^{[2]}$ Specifically, the lack of efficacy and the cognitive and behavioral consequences of WBRT have prompted clinicians to select patients for alternative therapies. ${ }^{[3]}$ Interestingly, radiosurgery provides a safe and effective treatment for many patients with brain metastases. ${ }^{[4]}$ An increasing number of patients are being referred for stereotactic radiosurgery (SRS) as the primary intervention for their intracranial pathological abnormalities ${ }^{[3]}$ and it is estimated that several thousands of cases with metastatic brain tumors have been treated with Gamma Knife radiosurgery (GKRS) so far. ${ }^{[5]}$

Brainstem metastasis, specifically, is an uncommon complication of systemic cancer and is generally considered to have a highly unfavorable prognosis. Its management includes standard radiation and chemotherapy, while surgical resection is not a routine procedure due to its high risks. ${ }^{[4,6,7]}$ For these patients SRS (GKRS) is nowadays used as a feasible treatment option and is considered as a treatment modality expected to achieve a radical cure. ${ }^{[7,8]}$ Furthermore, GKRS is an effective therapy (a non-invasive alternative to surgery) for primary brainstem tumors. ${ }^{[9]}$ The pons is the common-

\footnotetext{
*Correspondence: Ioannis N. Mavridis; Email: pap-van@otenet.gr; Address: Department of Neurosurgery, “K.A.T.-N.R.C.” General Hospital of Attica, Nikis str. 2, Kifissia, 14561 Athens, Greece.
} 
est location of brainstem metastases (primarily from lung cancer), with a frequency ranging from $51.85 \%$ to $79.25 \%$ (see Table 1). ${ }^{[4,6-8,10-14]}$ The purpose of this review is to explore the role of radiosurgery in the management of pontine metastases.

Table 1. Proportion of pontine location of metastatic foci among several reported series of patients with brainstem metastases

\begin{tabular}{lll}
\hline Authors & Year of publication & Pontine location (\%) \\
\hline Huang et al. ${ }^{[4]}$ & 1999 & 77.77 \\
Fuentes et al. ${ }^{[6]}$ & 2006 & 60.71 \\
Yen et al. ${ }^{[10]}$ & 2006 & 79.25 \\
Kased et al. ${ }^{[11]}$ & 2008 & 70.45 \\
Lorenzoni et al. ${ }^{[12]}$ & 2009 & 51.85 \\
Yoo et al. ${ }^{[7]}$ & 2011 & 71.88 \\
Li et al. ${ }^{[13]}$ & 2012 & 65.63 \\
Kawabe et al. ${ }^{[8]}$ & 2012 & 54.50 \\
Sengöz et al. ${ }^{[14]}$ & 2013 & 65.22 \\
& Mean value & 66.36 \\
\hline
\end{tabular}

\section{Methods}

Methodologically, a careful search of the literature was applied focusing on the role of radiosurgery in the management of patients suffering from pontine metastases. The main part of this search was a combined looking for the terms "radiosurgery" and "pontine metastases" in PubMed. It should be noted that the available data regarding the application of radiosurgery for treating patients with pontine metastases are remarkably restricted. Most of the information comes from studies reporting management of secondary brainstem tumors without focusing on a specific brainstem part.

\section{RESUlts}

\subsection{Patients' series}

During 1999-2013, nine patients' series ${ }^{[4,6-8,10-14]}$ with brainstem metastases treated with SRS (GKRS) were reported. The samples of these studies varied between 25-200 patients and the number of irradiated lesions ranged from 26 to 222 tumors. The majority of these metastases (ranging from 17 to 121 metastases) were actually located in the pons. The age of these patients varied between 25-86 years. The commonest primary malignancies included lung cancer, breast cancer, malignant melanoma, kidney cancer and gastrointensinal cancer (mainly colorectal cancer) while in some rare cases the primary location remained undetermined. A proportion of patients reaching up to $28.57 \%$ presented with at least two (and up to five) metastatic brainstem foci. $^{[4,6-8,10-14]}$

The marginal dose applied to these patients ${ }^{[4,6-8,10-14]}$ varied 16 between 6-30 Gy, while the mean marginal dose applied varied between 15.9-20 Gy. The volume of the irradiated brainstem lesions ranged between $0.005-21 \mathrm{~cm}^{3}$. The survival rates of these patients ranged between 1-32 months, while the median survival rate after GKRS in these series was approximately $9 \pm 2$ months. Moreover, local control rates of brainstem tumors following SRS was $81.8 \%-96 \%$. It should be noted here that some of the reported patients received additional treatments (prior or post-SRS), mainly fractionated WBRT. ${ }^{[4,6-8,10-14]}$

In the aforementioned series, ${ }^{[4,6-8,10-14]}$ the SRS was proved as a safe and effective therapy for patients with brainstem (and specifically pontine) metastases, allowing for a good neurologic condition of the patient, ${ }^{[8]}$ prolongation of survival with low associated risks ${ }^{[10]}$ and without a higher risk for radiation necrosis. ${ }^{[14]}$ Lack of patient's benefit or even clinical/radiological deterioration, brainstem complications $\left(9.52 \%{ }^{[11]}\right)$, transient peritumoral edema (one patient ${ }^{[13]}$ ) and latent tumor enlargement, were reported as SRS complications in a restricted number of these patients. ${ }^{[4,7,8,10,11,13,14]}$ No radiation-related morbidity of GKRS, however, was observed in some series. ${ }^{[6,12]}$

Finally, the prognostic factors of these patients included the patient's clinical status (the most crucial factor), the severity of systemic diseases, the tumor's histological type (worse prognosis for melanoma and renal cell carcinoma histology), the volume of the metastatic lesion (worse for lesions $\geq$ $1 \mathrm{~cm}^{3}$ ), control of primary tumor, absence of radiotherapy (associated with better survival) and a marginal dose $>$ 18 Gy (associated with better survival). ${ }^{[7,10-12]}$

Table 2 summarizes the reported mean/median doses and respective median survival of patients with brainstem metastases, mainly located in the pons, treated with SRS, according to the above mentioned patients' series.

\subsection{Other data}

Suki et al. $(2008)^{[15]}$ studied 379 patients with metastatic posterior fossa lesions that were treated with either resection or SRS and found that piecemeal tumor resection (137 cases) was associated with a significantly higher risk of leptomeningeal disease than en bloc resection (123 cases) or SRS and, interestingly, that there is no significant difference in the risk for leptomeningeal disease between en bloc resection and SRS. ${ }^{[15]}$

An interesting case of a 63-year-old woman who presented with a metastatic focus of papillary thyroid carcinoma in the cerebellopontine angle, manifesting as lateral gazing nystagmus and slurred speech, was recently reported by Tanaka et al. (2013). ${ }^{[16]}$ The patient underwent subtotal excision 
of the tumor and adjuvant GKRS. Her clinical course was unremarkable, and, noticeably, her hypoacusis and ataxia resolved completely. ${ }^{[16]}$

Tago et al. (1997) ${ }^{[5]}$ described two autopsy cases of metastatic brain tumors which had been treated with Gamma Knife. The first case was a 58-year-old woman diagnosed with multiple brain metastases from breast cancer. One of these lesions was in the medulla oblongata. The second case was a 69-year-old man diagnosed with multiple brain metastases from lung cancer. One of these lesions was in the pons. In both cases, the irradiated lesions were well demarcated from the undamaged surrounding tissues on light microscopy. Histologically, the tumor cells showed a variety of degenerative changes, such as pyknosis, multinuclear cells and vacuolar degeneration in the cytoplasm. Fibrosis, more prominent in the first case, was observed spreading in the irradiation field, adhering to the hyalinized and thickened vessel walls. ${ }^{[5]}$

Table 2. Reported marginal dose and respective median survival of patients with brainstem metastases (mainly located in the pons) treated with radiosurgery

\begin{tabular}{|c|c|c|c|}
\hline $\begin{array}{l}\text { Authors, year of } \\
\text { publication }\end{array}$ & Number of patients & Marginal dose (Gy) & $\begin{array}{l}\text { Median survival after } \\
\text { radiosurgery (months) }\end{array}$ \\
\hline Huang et al. ${ }^{[4]}, 1999$ & 26 & 16.0 (median), range: $12-20$ & 9.0 \\
\hline Fuentes et al. ${ }^{[6]}, 2006$ & 28 & 19.6 (mean), range: 11-30 & 12.0 \\
\hline Yen et al. ${ }^{[10]}, 2006$ & 53 & 17.6 (mean), range: 9-25 & 11.0 (range: 1-25) \\
\hline Kased et al. ${ }^{[11]}, 2008$ & 42 & 16.0 (median), range: $10-19.8$ & 9.0 \\
\hline Lorenzoni et al. ${ }^{[12]}, 2009$ & 25 & 20.0 (mean), range: $15-24$ & 11.1 \\
\hline Yoo et al. ${ }^{[7]}, 2011$ & 32 & 15.9 (mean), range: 6-23 & $7.7^{*}$ (range: $1-22$ ) \\
\hline Li et al. ${ }^{[13]}, 2012$ & 28 & 16.0 (median), range: $12-20$ & 9.0 (range: 2-32) \\
\hline Kawabe et al. ${ }^{[8]}, 2012$ & 200 & 18.0 (median), range: $12-25$ & 6.0 (range: 5.1-11.2) \\
\hline \multirow[t]{2}{*}{ Sengöz et al. ${ }^{[14]}, 2013$} & 44 & 16.0 (median), range: $10-20$ & 8.0 \\
\hline & & Mean value & 9.2 \\
\hline
\end{tabular}

Note. ${ }^{*}$ mean survival

Finally, Lavine et al. (1999) ${ }^{[3]}$ analyzed the effectiveness of Leksell Gamma unit therapy for metastatic melanoma to the brain. In their series, only $1 \%$ (1/93 lesions) was brainstem metastasis and specifically pontine, with the vast majority being located in the cerebral cortex. ${ }^{[3]}$ For these patients, as for patients with pontine metastases, GKRS seems to be a relatively safe, noninvasive, palliative therapy. ${ }^{[3]}$

\section{Discussion}

Pontine location is quite common among metastatic foci of the brainstem and perhaps this observation is partly due to the larger (compared to that of medulla oblongata and midbrain) volume of the pons. The available in the literature data about SRS applied for the management of secondary pontine tumors are restricted and come mostly from studies regarding the use of radiosurgery for treating patients with metastatic tumors of the brainstem. SRS currently constitutes an important option in the management of these patients as a safe and effective non-invasive treatment. It can offer prolongation of survival with low complications rate as a remarkable advantage over conventional surgery. According to the current literature, ${ }^{[4,6-8,10-14]}$ the mean dose used for this purpose is approximately $17.2 \mathrm{~Gy}$ and the achieved median survival of the treated patients is approximately nine months. The larger volume of lesions and some specific histological types of cancer (such as melanoma and renal cancer) seem to have poor prognosis. The clinical status of the patient, however, is actually more crucial for the patients' prognosis. Further research is needed for the optimization of the current SRS methods, including factors that affect the effectiveness of this treatment approach, in order to achieve better survival rates. Additionally, more and larger series could provide a clearer image of the advantages of SRS in the management of patients with pontine metastases.

\section{Conclusions}

Pontine metastases are the commonest type (2/3) of brainstem metastases, which are an uncommon type of secondary brain tumors with poor prognosis. Beside other treatment efforts, SRS has nowadays a major role in the management of these patients as a safe and effective treatment option that prolongs survival with low complications rate. The patient's clinical status seems to be an important determinant of survival.

\section{Conflicts of InTERest Disclosure}

The author declares that he has no competing interests. 


\section{REFERENCES}

[1] Greenberg MS. Handbook of Neurosurgery, 6th ed. New York: Thieme; 2006. 485, 488, 489 p.

[2] Manon R, O'Neill A, Knisely J, et al. Phase II trial of radiosurgery for one to three newly diagnosed brain metastases from renal cell carcinoma, melanoma, and sarcoma: an Eastern Cooperative Oncology Group study (E 6397). J Clin Oncol. 2005; 23(34): 8870-6. PMid: 16314647. http://dx.doi.org/10.1200/JC0.2005.01.8747

[3] Lavine SD, Petrovich Z, Cohen-Gadol AA, et al. Gamma knife radiosurgery for metastatic melanoma: an analysis of survival, outcome, and complications. Neurosurgery. 1999; 44(1): 59-64; discussion 64-6. PMid: 9894964. http://dx.doi.org/10.1097/0000612 3-199901000-00031

[4] Huang CF, Kondziolka D, Flickinger JC, et al. Stereotactic radiosurgery for brainstem metastases. J Neurosurg. 1999; 91(4): 563-8. PMid: 10507375. http://dx.doi.org/10.3171/jns.1999.91 .4 .0563

[5] Tago M, Aoki Y, Nakagawa K, et al. [Gamma knife radiosurgery for metastatic brain tumors: neuropathological report of two autopsy cases and review of literatures]. Nihon Igaku Hoshasen Gakkai Zasshi. 1997; 57(3): 119-26. Japanese. PMid: 9077094.

[6] Fuentes S, Delsanti C, Metellus P, et al. Brainstem metastases: management using gamma knife radiosurgery. Neurosurgery. 2006; 58(1): 37-42. PMid: 16385327. http://dx.doi.org/10.1227/01. NEU. $0000190655.95669 .5 \mathrm{C}$

[7] Yoo TW, Park ES, Kwon do H, et al. Gamma knife radiosurgery for brainstem metastasis. J Korean Neurosurg Soc. 2011; 50(4): 299-303. PMid: 22200010. http://dx.doi.org/10.3340/jkns. 2011.5 0.4 .299

[8] Kawabe T, Yamamoto M, Sato Y, et al. Gamma Knife surgery for patients with brainstem metastases. J Neurosurg. 2012; 117 Suppl: 23-30. PMid: 23205785. http://dx.doi.org/10.3171/2012.7. GKS12977
[9] Ding D, Starke RM, Kano H, et al. Gamma knife radiosurgery for cerebellopontine angle meningiomas: a multicenter study. Neurosurgery. 2014; 75(4): 398-408. PMid: 24991710. http://dx.doi . org/10.1227/NEU. 0000000000000480

[10] Yen CP, Sheehan J, Patterson G, et al. Gamma knife surgery for metastatic brainstem tumors. J Neurosurg. 2006; 105(2): 213-9. PMid: 17219825 . http://dx.doi.org/10.3171/jns.2006.10 5.2 .213

[11] Kased N, Huang K, Nakamura JL, et al. Gamma knife radiosurgery for brainstem metastases: the UCSF experience. J Neurooncol. 2008; 86(2): 195-205. PMid: 17628747. http://dx.doi.org/10.1007 /s11060-007-9458-4

[12] Lorenzoni JG, Devriendt D, Massager N, et al. Brain stem metastases treated with radiosurgery: prognostic factors of survival and life expectancy estimation. Surg Neurol. 2009; 71(2): 188-95; discussion 195, 195-6. PMid: 18439658. http://dx.doi.org/10.1016/j .surneu.2008.01.029

[13] Li Y, Xu D, Zhang Z, et al. Gamma Knife surgery for brainstem metastases. J Neurosurg. 2012; 117 Suppl: 13-6. PMid: 23205783. http://dx.doi.org/10.3171/2012.7.GKS121020

[14] Sengöz M, Kabalay IA, Tezcanlı E, et al. Treatment of brainstem metastases with gamma-knife radiosurgery. J Neurooncol. 2013; 113(1): 33-8. PMid: 23443514. http://dx.doi.org/10.1007 /s11060-013-1086-6

[15] Suki D, Abouassi H, Patel AJ, et al. Comparative risk of leptomeningeal disease after resection or stereotactic radiosurgery for solid tumor metastasis to the posterior fossa. J Neurosurg. 2008; 108(2): 248-57. PMid: 18240919. http://dx.doi.org/10.3171 /JNS/2008/108/2/0248

[16] Tanaka T, Kato N, Aoki K, et al. Cerebellar hemorrhage secondary to cerebellopontine angle metastasis from thyroid papillary carcinoma. Neurol Med Chir (Tokyo). 2013; 53(4): 233-6. PMid: 23615414 http://dx.doi.org/10.2176/nmc.53.233 